\title{
Benchmarks for submerged structure response to underwater explosions
}

\author{
Hans U. Mair \\ Institute for Defense Analyses, Operational \\ Evaluation Division, 1801 North Beauregard Street, \\ Alexandria, VA 22311-1772, USA \\ E-mail:mairh@asme.org \\ Received 12 November 1998 \\ Revised 28 July 1999
}

Benchmarks for submerged structure response to underwater explosions (UNDEX) are compiled. Both analytical and empirical benchmarks are presented; each type has advantages and disadvantages for the purposes of model validation, though no methodology for employing these benchmarks in a model validation effort is proposed. Benchmark computations are also referenced as part of this compilation. Finally, extension of this compilation to the UNDEX response of internal equipment and floating structures, and to hydrodynamic/hydraulic ram problems, is proposed.

\section{Overview}

A set of underwater explosion (UNDEX) benchmarks is compiled, in the spirit of similar compilations [1-4], and in the interest of initiating a dialog within the UNDEX community on validation techniques. Focus is limited to the response of submerged structures to underwater explosions (including structures and explosions in saturated sand), and only unclassified data are included.

Use of the term "benchmarks" is admittedly not consistent with that in the more mature fields of computational fluid and structural dynamics, in which the term is applied only to data of quantified high accuracy and repeatability. It is deemed necessary here to include data being employed as benchmarks, even though their accuracy and repeatability have not been quantified.

Both analytical and empirical benchmarks are presented; each type has advantages and disadvantages. One issue raised in this compilation is the quality and applicability of validational data, specifically the added value of converged analytical models, replicate experiments, and quantification of empirical scatter. This document does not propose a methodology for employing these benchmarks in a model validation effort.

Several tables summarize the characteristics of the benchmarks, and a table of benchmark computations is also presented. For simplicity, a binary identification is employed, where • = "yes", and o = "no". In this preliminary compilation, the minimal detail provided about the benchmarks does not include response characteristics. Such characterization would be extremely useful for identifying phenomena of interest to the community, benchmark limitations and applicability, and duplicate and missing benchmark data.

\section{Descriptions of benchmark problems}

Two classes of benchmarks are described: analytical (summarized in Table 1) and empirical (summarized in Table 2). One-dimensional (1D) benchmark data provide the simplest and most affordable validation, but cannot exhibit many of the phenomena of greatest interest to the underwater explosion structure/medium interaction community. Two-dimensional (2D) benchmarks can exhibit many of the phenomena of interest to the underwater explosion structure/medium interaction community. Some phenomena of interest to the underwater explosion structure/medium interaction community can only be exhibited in 3D (e.g., failure and fracture of stiffened cylinders); however, computational modeling of 3D events is more demanding than that of $1 \mathrm{D}$ and $2 \mathrm{D}$ events. Continuum dynamics and structure/medium interaction benchmarks are described in more detail in Table 3 and Table 4, respectively.

\subsection{Analytical benchmarks}

Analytical benchmarks, listed in Table 1, are not experiments. Ideally, they are the solution to a system of mathematical equations with appropriate bound- 
Table 1

Overview of analytical benchmarks

\begin{tabular}{|c|c|c|c|c|c|c|c|}
\hline & 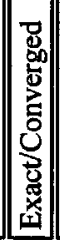 & 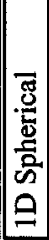 & 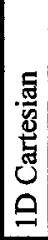 & 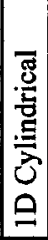 & 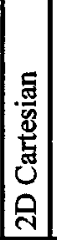 & 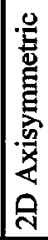 & 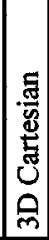 \\
\hline Shock Tube & 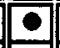 & 0 & 0 & 0 & Oा & 0 & 0 \\
\hline Rayleigh-Plesset Solution & $\bullet$ & e & 0 & 0 & 0 & 0 & 0 \\
\hline Primakoff Solution & $\bullet$ & e & 0 & 0 & 0 & 0 & 0 \\
\hline Cavitated Water Impact & - & 0 & - & 0 & 0 & 0 & 0 \\
\hline P-alpha Shock Tube & $\bullet$ & 0 & $\bullet$ & 0 & 0 & 0 & 0 \\
\hline Wardlaw/Mair Bubble & 0 & - & 0 & 0 & 0 & 0 & 0 \\
\hline Taylor Plate & 0 & 0 & 0 & 0 & O & 0 & 0 \\
\hline Schechter/Bort Plates & 0 & 0 & - & 0 & 인 & 0 & 0 \\
\hline Snay/Christian Plate & $\mathrm{O}$ & 0 & 0 & 0 & O & 0 & 0 \\
\hline Bleich/Sandler Plate & 0 & 0 & - & 0 & 0 & 0 & 0 \\
\hline Huang Plate & 0 & 0 & 0 & 0 & O & - & 0 \\
\hline Murray Cylinder & $\bullet$ & 0 & 0 & 0 & $\bullet$ & $\mathrm{O}$ & 0 \\
\hline Huang Sphere & 0 & 0 & 0 & 0 & 이 & - & 0 \\
\hline Huang Concentric Spheres & 0 & 0 & 0 & 0 & 0 & - & 0 \\
\hline Huang Cylinder & 0 & 0 & 0 & 0 & $\bullet$ & 0 & - \\
\hline Huang Concentric Cylinders & 0 & 0 & 0 & 0 & $\bullet$ & 0 & 0 \\
\hline Zhang/Geers Sphere & $\mathrm{O}$ & 0 & 0 & 0 & 0 & 0 & 0 \\
\hline Jones-Oliveira Shell & 0 & 0 & 0 & 0 & 인 & 0 & $\bullet$ \\
\hline
\end{tabular}

ary/initial conditions. In practice, they are often approximations to the solution, since for realistic problems some sort of discretization is employed. Discretization of space and time, for example, results in simple solutions that are pieced together to approximate a continuous solution. Examples of this approach include the finite element, finite difference, and finite volume methods, as well as the method of characteristics. An alternative approach is to discretize the solution into a series that represents "response modes", a finite number of which are employed to approximate the solution. An analytical benchmark that employs the discretization process is most useful if a converged solution has been obtained. Unconverged analytical benchmarks are included in this compilation, but should be considered less reliable than the converged analytical benchmarks. If convergence has been demonstrated, analytical benchmarks are particularly suitable for the validation of computational models, since an "error measure" can be employed [5-8].

\section{Analytical continuum dynamics benchmarks}

- Shock Tube is a 1D cartesian Riemann Solution of shock and rarefaction (expansion) wave propa-
Table 2

Overview of empirical benchmarks

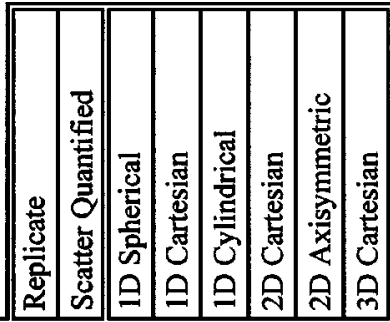

\begin{tabular}{|c|c|c|c|c|c|c|c|c|}
\hline$\overline{\text { UNDEX Sil }}$ & 10 & $\bullet$ & $\overline{0}$ & 0 & Oा & 0 & 0 & $\overline{\mathrm{O}}$ \\
\hline Spark-Generated Bubbles & 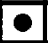 & 이 & $\bullet$ & 0 & 0 & 0 & - & \\
\hline SRI Spherical S & 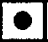 & 이 & 0 & 0 & 0 & 0 & 0 & $\underline{0}$ \\
\hline Snay/Goertn & 0 & 잉 & 인 & 0 & O & 0 & 0 & \\
\hline$\overline{\text { SAI }}$ & 0 & 잉 & 0 & $\mathrm{O}$ & o & 0 & 0 & 0 \\
\hline WEAG & 0 & 잉 & 이 & 0 & 이 & 0 & $\bullet$ & \\
\hline Seneca Lake & 0 & 잉 & o & 0 & 0 & 0 & $\bullet$ & \\
\hline SBSI & 0 & 잉 & 이 & 0 & O & 0 & 0 & \\
\hline Pipe V & 0 & 0 & 인 & 0 & 인 & 0 & 0 & \\
\hline Dynaflow Wat & 0 & 이 & o & $\mathrm{O}$ & 0 & 0 & 0 & \\
\hline IFM & 0 & 0 & 이 & 0 & 0 & 0 & 0 & \\
\hline IED & 0 & 0 & 0 & 0 & 0 & 0 & 0 & \\
\hline gen ? & 0 & 이 & 0 & 0 & 0 & 0 & 0 & \\
\hline $\mathrm{RCy}$ & 0 & 0 & 이 & 0 & 0 & 0 & 0 & \\
\hline $\mathrm{mbir}$ & 0 & 이 & 0 & 0 & 0 & 0 & 0 & 0 \\
\hline$\overline{3 T}$ & 0 & 잉 & 0 & 0 & 0 & 0 & 인 & \\
\hline HTE & 0 & 이 & 0 & 0 & 0 & 0 & 0 & \\
\hline DUS & 0 & 이 & 이 & 0 & 0 & 0 & 0 & $\bullet$ \\
\hline int Surfac & 0 & 0 & 0 & 0 & 0 & 0 & 을 & 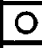 \\
\hline GHBC & 0 & 0 & 0 & 0 & 0 & 0 & - & 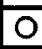 \\
\hline DRES & 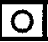 & 0 & 0 & 0 & 0 & 0 & & 0 \\
\hline
\end{tabular}

gation resulting from interaction of two fluids initially at rest. APRICOT [9] is such a solution.

- Rayleigh-Plesset [10] is a 1D spherical solution for incompressible liquid bubble dynamics.

- Primakoff [11] is a 1D spherical solution of shock wave propagation in a water-like material due to the presence of a moving boundary.

- Cavitated Water Impact [12] is a 1D cartesian solution of the impact of cavitated water on a rigid boundary.

- P-alpha Shock Tube [13] is a Riemann Solution of shock and rarefaction (expansion) wave propagation resulting from interaction of two states of a porous solid (modeled with the P-alpha equation of state) initially at rest.

- Wardlaw/Mair Bubble [14,15] is a set of converged 1D spherical computational fluid dynamics solutions of underwater explosion bubble dynamics for various initial conditions and solution methods. 
Table 3

Continuum dynamics benchmarks

\begin{tabular}{|c|c|c|c|c|c|c|c|}
\hline & 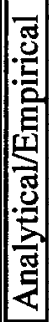 & 离 & 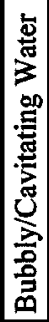 & 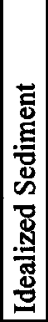 & 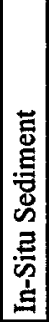 & 当 & 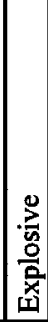 \\
\hline Shock Tube & $\mathbf{A}$ & 0 & 0 & 0 & 0 & 0 & 0 \\
\hline Rayleigh-Plesset Solution & A & 0 & 0 & 0 & $\mathrm{O}$ & 0 & 0 \\
\hline Primakoff Solution & $\mathbf{A}$ & 0 & 0 & 0 & 0 & 0 & 0 \\
\hline Cavitated Water Impact & $\mathbf{A}$ & 0 & 0 & 0 & 0 & 0 & 0 \\
\hline P-alpha Shock Tube & $\mathbf{A}$ & 0 & 0 & 9 & 0 & 0 & 0 \\
\hline Wardlaw/Mair Bubble & A & - & 0 & 0 & 0 & 0 & 0 \\
\hline UNDEX Similitude & $\mathbf{E}$ & 2 & 0 & 0 & 0 & 0 & 0 \\
\hline Spark-Generated Bubbles & $\mathrm{E}$ & 0 & 0 & 0 & 0 & 0 & 0 \\
\hline SRI Spherical Sand Shock & $\mathbf{E}$ & 0 & 0 & 0 & $\mathrm{O}$ & 0 & 0 \\
\hline Snay/Goertner Bubble & $\mathbf{E}$ & 0 & 0 & 0 & 0 & 0 & 0 \\
\hline
\end{tabular}

\section{Analytical structure/medium interaction benchmarks}

- Taylor Plate [16] is a 1D cartesian analytical solution of weak shock interaction with an air-backed plate; the water is modeled as a linear fluid with no allowance for cavitation, so an exact solution is obtained.

- Schechter/Bort Plates [17] is a 1D cartesian analytical solution of weak shock interaction with fluid-coupled plates, with the second plate either air-backed or water-backed; the water is modeled as a linear fluid with no allowance for cavitation, so an exact solution is obtained.

- Snay/Christian Plate [18] is a 1D cartesian analytical solution of strong shock interaction with an air-backed plate; the water is modeled as a nonlinear fluid with no allowance for cavitation. The solution is obtained using the method of characteristics.

- Bleich/Sandler Plate [19] is a 1D cartesian analytical solution that captures the occurrence of cavitation in water due to weak shock interaction with an air-backed plate; the water is modeled as a bilinear fluid. The solution is obtained using the method of characteristics.

- Huang Plate [20] is a 2D axisymmetric analytical solution of weak spherical shock interaction with an air-backed plate with no allowance for cavitation.
Table 4

Structure/medium interaction benchmarks

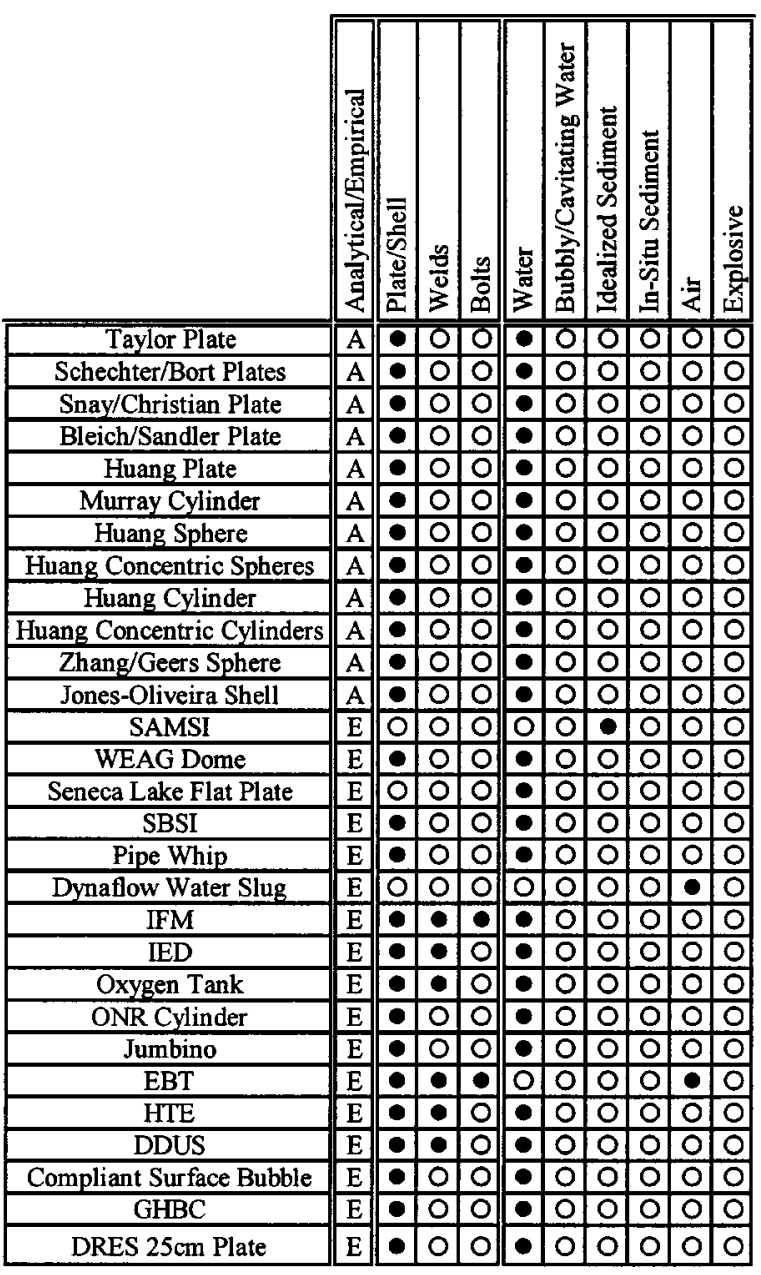

- Murray Cylinder [21] is a 2D cartesian analytical solution to the rigid body translational response of a cylinder to a plane underwater shock wave.

- Huang Sphere [22-24] is a 2D axisymmetric solution of the elastic response of submerged structures to weak shock waves. A fully converged solution has recently been obtained [24] that differs little from the previously obtained solution.

- Huang Concentric Spheres [25] is a 2D axisymmetric solution of the elastic response of submerged structures to weak shock waves.

- Huang Cylinder [26,27] is a 2D and 3D cartesian solution of the elastic response of submerged structures to weak shock waves.

- Huang Concentric Cylinders [28] is a 2D cartesian solution of the elastic response of submerged structures to weak shock waves. 
- Zhang/Geers Sphere [29-31] is a 2D axisymmetric solution of the elastic response of a fluid-filled sphere to weak water shock waves.

- Jones-Oliveira Shell [32,33] is a 3D solution of the elastic response of a submerged prolate spheroidal shell to weak shock waves.

\subsection{Empirical benchmarks}

Empirical benchmarks, listed in Table 2, are based upon experiments. They may represent a single experiment or multiple experiments. They are most valuable when presented with statistical information quantifying the means and spreads of the measurements. Empirical benchmarks are far more valuable if accuracy of the data has been established; unfortunately, this issue is not addressed in any of the examples.

\section{Empirical Continuum Dynamics Benchmarks}

- UNDEX Similitude [34] is a spherical 1D compilation of many UNDEX experiments, from which performance parameters are derived for various explosives. Additionally, the scatter in the experimental data has been statistically quantified.

- Spark-Generated Bubbles [35-41] are bubbles generated by sparks in water, for the purpose of simulating underwater explosions.

- SRI Spherical Sand Shock [42] is a spherical 1D set of experiments of detonation in sand in various states of saturation.

- Snay/Goertner Bubble [43] experiments are underwater explosion bubbles influenced by a nearby, rigid cylinder.

Empirical structure/medium interaction benchmarks

- SAMSI (Sand and Mine Structure Interaction) $[44,45]$ experiments are thick-walled cylinders with a flat, air-backed end plate subjected to axisymmetric sediment shock loading.

- WEAG (Western European Armaments Group) Dome [46] is a domed, air-backed structure subjected to underwater shock and bubble jetting loading from above (gravity vector is aligned with the structural axis of symmetry); the $2 \mathrm{D}$ version is unstiffened, while the $3 \mathrm{D}$ version is asymmetrically stiffened.

- Seneca Lake Flat Plate experiments $[47,48]$ are flat, circular, horizontally placed, water-backed plate subjected to underwater shock and bubble collapse loading from below (gravity vector is aligned with the structural axis of symmetry). The axisymmetric experiments were conducted in the NSWC Hydrotank in Silver Spring in Mary- land, and the 3D (asymmetrically stiffened) experiments were conducted at Seneca Lake in New York State.

- SBSI (Schmidt Bubble/Structure Interaction) experiments [49] are rectangular, vertically placed, water backed plates subjected to shock and bubble collapse loading from the side (gravity vector is not aligned to the charge/plate axis).

- Pipe Whip [50] experiments are cylinders (with a stiffened test section) subjected to shock and bubble pulse loading resulting in whipping response.

- Dynaflow Water Slug [51] experiments are slugs of water fired at flexible rectangular plates.

- IFM (Internal Fluid Model) [52] experiments are concentric cylinders, with water entrained between the inner and outer cylinders, subjected to large standoff water shock loading. A preliminary test was conducted on a single cylinder.

- IED (Independent Exploratory Development) [53] experiments are unstiffened cylinders subjected to small standoff water shock loading.

- Oxygen Tank [54] experiments are externally stiffened cylinders subjected to large standoff water shock loading.

- ONR Cylinder [55] experiments are cylinders subjected to large standoff water shock loading.

- Jumbino [56] experiments are thick-walled, waterfilled axisymmetric structures subjected to internal blast.

- EBT (Explosion Bulge Test) [57] is a class of experiments in which thick circular plates with welds are subjected to explosion loading in air.

- HTE (Hull Toughness Element) [58] is a class of experiments in which thick, welded, precracked plates are subjected to underwater explosion loading.

- DDUS (Deep Depth UNDEX Simulator) [59] experiments are a set of experiments in which stiffened cylinders, housed within a pressurized outer chamber to simulate deep depth, are subjected to large-standoff water shock loading.

- Compliant Surface Bubble [60] is a 2D axisymmetric set of experiments of bubble collapse onto a compliant surface composed of rubber materials.

- GHBC (Guirguis Hydro-Bulged Cylinder) [61, $62]$ is a $2 \mathrm{D}$ axisymmetric set of experiments of water-filled structures subjected to internal blast.

- DRES (Defence Research Establishment, Suffield) $25 \mathrm{~cm}$ Plate [63] is a series of 2D axisymmetric experiments of bubble interaction with a circular metal plate. 


\section{Benchmark computations}

Benchmark computations, compiled in Table 5, are organized by both code and benchmark. Precautions in evaluating validation computations are also outlined.

\subsection{Benchmark computations organized by code}

Codes are grouped into three categories: Doubly Asymptotic Approximation (DAA) codes, hydrocodes, and other types of approaches.

\section{Benchmark computations employing DAA codes}

DAA codes are structural dynamics codes employing the Doubly Asymptotic Approximation (DAA) [64-66], a robust structure-medium interaction (SMI) approximation that is asymptotically exact in both the low-frequency and high-frequency limits. In finiteelement response calculations, it provides a set of ordinary differential equations (ODEs) for the SMI that are solved in tandem with the response ODEs for the dry structure. The inputs for a typical UNDEX calculation are the incident-wave pressure and velocity fields, i.e., those that would exist in the absence of the structure.

- The ADINA-S special-purpose shock/structure interaction code $[67,68]$, in which an implementation of the DAA provides the fluid/structure interaction loads for the ADINA structural dynamics code, was exercised on a Huang Sphere model [67], Huang Cylinder model [68], and Huang Concentric Cylinders model [68].

- The DYNA/FSI special-purpose shock/structure interaction code [69], in which an implementation of the DAA provides the fluid/structure interaction loads for the DYNA3D hydrocode, was exercised on a Bleich/Sandler Plate model [69], and Huang Sphere model [70,71].

- The ELSHOK special-purpose shock/structure interaction code [72-74], in which an implementation of the DAA provides the fluid/structure interaction loads for the elastic structural dynamics code, was exercised on an ONR Cylinder model [75-77].

- The EPSA special-purpose shock/structure interaction code [78-83], in which an implementation of the DAA provides the fluid/structure interaction loads for the elastic-plastic structural dynamics code, was exercised on a Huang Sphere model [83-85], Huang Concentric Spheres model [8385], IFM model [83,86-88], and DDUS model [89]. EPSA has recently been coupled to the FUSE Total Lagrangian hydrocode.
- The USA-ABAQUS special-purpose shock/structure interaction code [90], in which the USA (Underwater Shock Analysis) code implementation of the DAA provides the fluid/structure interaction loads for the ABAQUS structural dynamics code, was exercised on a Huang Sphere model [90].

- The USA/NASTRAN special-purpose shock/ structure interaction code [91], in which the USA (Underwater Shock Analysis) code implementation of the DAA provides the fluid/structure interaction loads for the NASTRAN structural dynamics code, was exercised on a Huang Concentric Spheres model [92], an ONR Cylinder model [93], and a Bleich-Sandler Plate model [94].

- The USA-STAGS-CFA special-purpose shock/ structure interaction code [95], in which the USA (Underwater Shock Analysis) code implementation of the DAA, and the CFA (Cavitating Fluid Analyzer) code, provide the fluid/structure interaction loads for the STAGS structural dynamics code, was exercised on a Schechter/Bort Plates model [96], Bleich/Sandler Plate model [97], Huang Sphere model [98], Huang Cylinder model [98-100], Huang Concentric Cylinders model [96,101,102], and ONR Cylinder model [103].

- The USA-VEC/DYNA3D special-purpose shock/ structure interaction code, in which the USA (Underwater Shock Analysis) code implementation of the DAA provides the fluid/structure interaction loads for the VEC/DYNA3D hydrocode, was exercised on an IFM model [86]. This capability is also available for the commercial version, LSDYNA.

Benchmark computations employing hydrocodes

"Hydrocodes" are computational mechanics codes capable of simulating wave propagation phenomena in both solids and fluids. As such, they are to be distinguished from computational fluid dynamics (CFD) codes, which are hydrodynamics or aerodynamics codes.

- The ALE3D multimaterial Arbitrary Lagrangian Eulerian (ALE) hydrocode [104] was compared with UNDEX Similitude [108], and exercised on a Seneca Lake Flat Plate model [105], Snay/ Goertner Bubble model [105], Pipe Whip model [105], and IED Cylinder model [105].

- The coupling of the CTH Eulerian hydrocode with the EPIC Lagrangian hydrocode through the 
Table 5

Compilation of benchmark computations

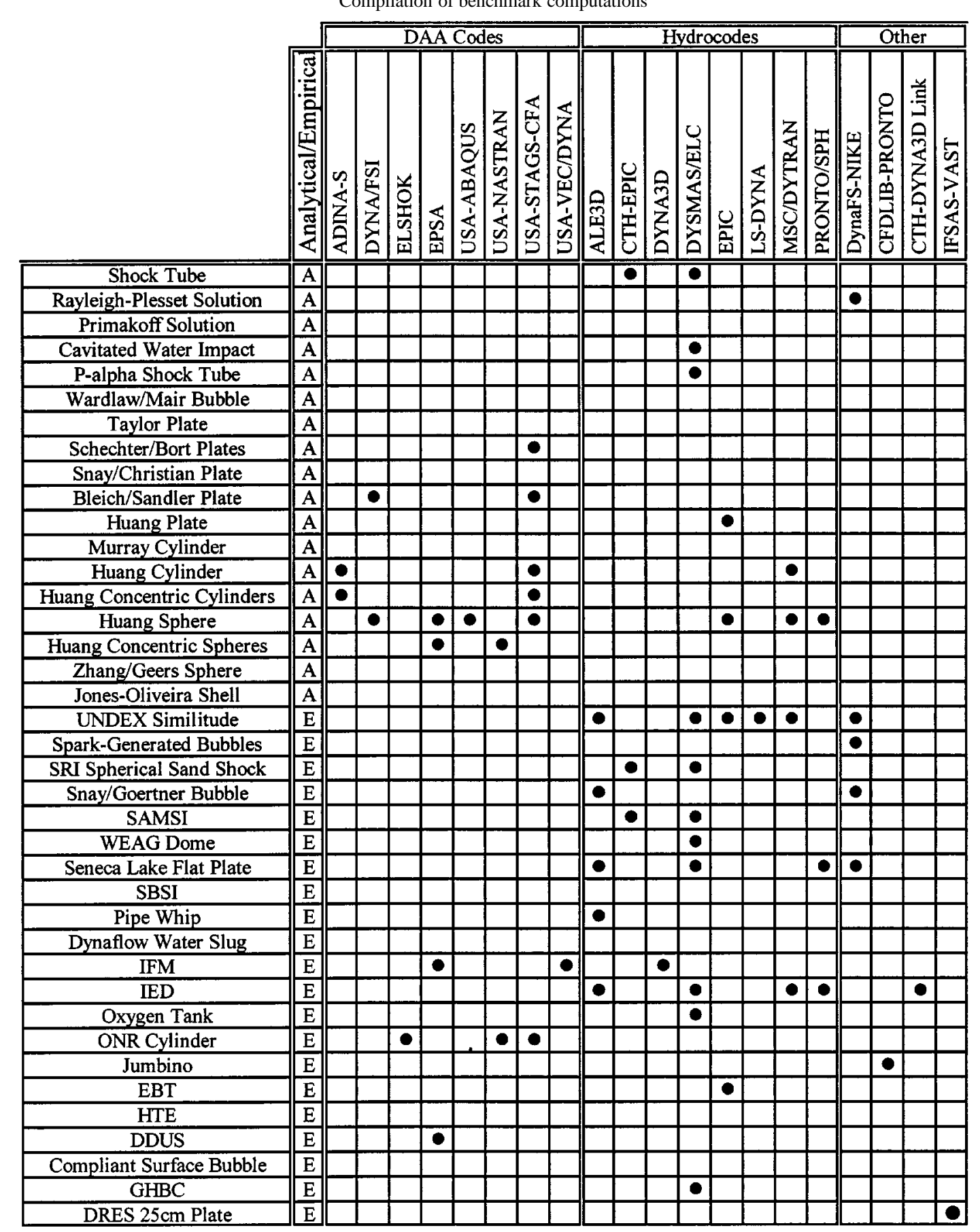

ZAPOTEC module [106,107] was exercised on a SAMSI model [13]; CTH, in standalone mode, was compared with UNDEX Similitude [108], and exercised on an SRI Spherical Sand Shock model [13].
- The DYNA3D Lagrangian hydrocode [109] was exercised on an IFM model [86].

- The DYSMAS/ELC Coupled Eulerian/Lagrangian (CEL) hydrocode [110] was exercised on a SAMSI model [44,45], WEAG Dome model [46], 
Seneca Lake Flat Plate model [111,112], IED model [113], Oxygen Tank model [54], and a GHBC model [114]. DYSMAS/E, in stand-alone mode, was exercised on Shock Tube problems (including Apricot \#1) [115,116], a Cavitated Water Impact model [117], SRI Spherical Sand Shock model [13], P-alpha Shock Tube model [13], and was compared with UNDEX Similitude [113].

- The EPIC hydrocode [118] was compared with UNDEX Similitude [119], and exercised on a Huang Plate model [120], Huang Sphere model [120], and an EBT model [121].

- The LS-DYNA Lagrangian hydrocode $[122,123]$ was exercised on an UNDEX Similitude model [108].

- The MSC/DYTRAN Coupled Eulerian/Lagrangian (CEL) and Arbitrary Lagrangian/Eulerian (ALE) hydrocode $[124,125]$ was compared with UNDEX Similitude [126], and exercised on a Huang Sphere model [126,127], Huang Cylinder model [126,127], and an IED Cylinder model [128].

- The PRONTO/SPH Lagrangian hydrocode with a Smoothed Particle Hydrodynamics (SPH) option [129] was exercised on a Huang Sphere model [130], IED Cylinder model [130], and Seneca Lake Flat Plate model [130].

Benchmark computations employing other codes

Other code types include uncoupled approaches, and traditional Computational Fluid Dynamics (CFD) codes coupled to structural response codes. CFD codes include Boundary Element Method (BEM) codes, which treat the fluid as incompressible and irrotational, allowing discretization of material interfaces only. CFD codes are also common in Eulerian or Arbitrary Lagrangian/Eulerian (ALE) formulations.

- The 2DynaFS special-purpose bubble/structure interaction code coupled to the NIKE2D structural dynamics code $[131,132]$ was exercised on a Seneca Lake Flat Plate model [133]. 2DynaFS and 3DynaFS, in stand-alone mode, have been exercised on a Rayleigh-Plesset Solution model [134], Snay/Goertner Bubble model [134-138], a Spark-Generated Bubbles model [138], a Seneca Lake Flat Plate model [132], and compared with UNDEX similitude [134].

- The CFDLIB family of fluid dynamics codes coupled to the PRONTO2D hydrocode [139-141] was exercised on a Jumbino model [56].
- The CTH-DYNA3D Link [142] is an uncoupled transfer of information from a CTH hydrocode model to a DYNA3D hydrocode model. It was exercised on an IED model [142].

- The BUB3D incompressible Eulerian fluid dynamics code [143] is not coupled to a structural dynamics code, but can prescribe the motion of a boundary. It was exercised on a Seneca Lake Flat Plate model [144] and a Snay/Goertner Bubble model [144].

- The IFSAS compressible CFD code [145] coupled to the VAST structural dynamics code was exercised on a DRES $25 \mathrm{~cm}$ Plate model [146].

\subsection{Benchmark computations organized by benchmark}

\section{Analytical benchmark computations}

- Shock Tube simulations include DYSMAS/E models [115,116], including Apricot \#1 [115].

- Rayleigh-Plesset Solution [10] simulations include a 2DynaFS model [134].

- Cavitated Water Impact [12] simulations include a DYSMAS/E model [117].

- P-alpha Shock Tube [13] simulations include a DYSMAS/E model [13].

- Schechter/Bort Plates [17] simulations include a USA-STAGS-CFA model [96].

- Bleich/Sandler Plate [19] simulations include a USA-STAGS-CFA model [97], a USA -NASTRAN-CFA model [94], and a DYNA/FSI model [69].

- Huang Plate [20] simulations include an EPIC model [120].

- Huang Sphere [22-24] simulations include an MSC/DYTRAN model [126,127], an EPSA model [83-85], a USA-STAGS-CFA model [98], a DYNA/FSI model [70,71], an EPIC model [119], a PRONTO/SPH model [130], and a USAABAQUS model [90].

- Huang Concentric Spheres [25] simulations include an EPSA model [78,83,84], and a USANASTRAN model [92].

- Huang Cylinder [26,27] simulations include an MSC/DYTRAN model [126,127], a USA -STAGS- CFA model [98-100], and an ADINA-S model [67].

- Huang Concentric Cylinders [28] simulations include an ADINA-S model [67], and USA -STAGS-CFA models [96,101,102]. 


\section{Empirical benchmark computations}

- UNDEX Similitude [34] simulations include a DYSMAS/ELC model [113], a CTH model [108], an MSC/DYTAN model [126], an ALE3D model [108], an EPIC model [119], an LS-DYNA model [108], and a 2DynaFS model [134].

- Spark-Generated Bubbles [35] simulations include a 3DynaFS model [138].

- SRI Spherical Sand Shock [42] simulations include a DYSMAS/ELC model [13], and a CTHEPIC model [13].

- Snay/Goertner Bubble [43] simulations include a 3DynaFS model [134-138], and an ALE3D model [105].

- SAMSI (Sand and Mine Structure Interaction) [44] simulations include a DYSMAS/ELC model [13] and a CTH-EPIC model [13].

- WEAG (Western European Armaments Group) Dome [46] simulations include a DYSMAS/ELC model [46].

- Seneca Lake Flat Plate $[47,48]$ simulations include a DYSMAS/ELC model [111,112], a 2DynaFS-NIKE2D model [133], an ALE3D model [105], and a PRONTO/SPH model [130].

- Pipe Whip [50] simulations include an ALE3D model [105].

- IFM (Internal Fluid Model) [52] simulations include an EPSA model [86-88], a USA-VEC/ DYNA model [86], and a DYNA3D model [86].

- IED (Independent Exploratory Development) [53] simulations include a DYSMAS/ELC model [113], an MSC/DYTRAN model [128], an ALE3D model [105], a PRONTO/SPH model [130], and a CTH-DYNA3D Link model [142].

- Oxygen Tank [54] simulations include a DYSMAS/ELC model [54].

- ONR Cylinder simulations include an ELSHOK model [75-77], a USA-NASTRAN model [93], and a USA-STAGS-CFA model [103].

- Jumbino [56] simulations include a CFDLIBPRONTO2D model [56].

- EBT (Explosion Bulge Test) [57] simulations include an EPIC model [121].

- DDUS (Deep Depth UNDEX Simulator) [59] simulations include an EPSA model [89].

- GHBC [61,62] simulations include a DYSMAS/ELC model [114].

- DRES $25 \mathrm{~cm}$ Plate [63] simulations include an IFSAS-VAST model [146].

\subsection{Caveat emptor}

Existence and documentation of a benchmark computation does not imply that a code was validated, or even that the model results were "good". For example, faulty results have been published:

- The original Huang Sphere publication [22] includes a slight error, as pointed out in [66], and corrected in [24].

- An EPSA model [83-85] of the Huang Sphere analytical benchmark [22] predicts large-amplitude, high-frequency oscillations superimposed on the fundamental response, theorized by the authors to be "real" since convergence had not been demonstrated in the Huang Sphere analytical solution. A more recent analysis [24] of the analytical benchmark, in which convergence was obtained, revealed that the large-amplitude, high-frequency oscillations predicted by the EPSA model were in error.

- A DYNA3D model of the IFM empirical benchmark [86] included a bug, resulting in some incorrect data generated. The faulty data were published, along with a note in the document indicating the presence of the bug. The faulty computational data were due to the computational model, not the DYNA3D code.

- A report describing a DYTRAN model of the IED Cylinder empirical benchmark [128] compares the simulated maximum deflection of the cylinder to the final deflection measured in the experiment. More recent analyses with DYSMAS/ELC [113] and ALE3D [105] show that significant elastic rebound is present, and that the agreement between the DYTRAN model results and experimental data was fortuitous.

In general, disagreement between computational model results and benchmark data does not imply a faulty code or even a faulty model; many sources of error exist in the generation of both computational and experimental data. Limitations on gauges and data reduction, and unknown response aspects (lack of material characterization, effects of welds, bolts, fixtures, etc.), are examples of issues that can significantly influence the value of experimental data. Modeling approximations and errors, and lack of discretization convergence, are examples of issues that can significantly influence the accuracy, and therefore the value, of computational data. 
Alternately, computational models can be so complex that results seeming to validate a model may be fortuitous. So many options are available in computational mechanics codes that offsetting errors should be expected.

This compilation of benchmarks is not complete; some of the codes have been extensively exercised on "classified" benchmarks, or on more complex empirical data that are not usually considered "benchmarks".

\section{Summary}

In the interest of initiating a dialog within the UNDEX community on validation techniques, a limited set of UNDEX benchmarks, and computations thereof, is presented. Extension of this database beyond the response of submerged structures to underwater explosions is proposed; natural extensions include the response of internal equipment and floating structures, as well as hydrodynamic ram problems.

\section{Acknowledgments}

This update of previous work was sponsored by the Office of the Secretary of Defense, Deputy Director, Operational Test and Evaluation, Live Fire Testing (Mr J.F. O'Bryon). The previous effort was funded by the Office of Naval Research while the author was employed by the Naval Surface Warfare Center, Indian Head Division (White Oak). The author is indebted to S. Zilliacus of the Naval Surface Warfare Center, Carderock Division, and H. Huang, W. McDonald, M. Mair, and E. Johnson of the Naval Surface Warfare Center, Indian Head Division, for reviewing the document and providing helpful suggestions. Significant input was also provided by D. Ranlet (Weidlinger Associates), J. DeRuntz (Unique Software Applications), and G. Chahine (Dynaflow Inc.).

\section{References}

[1] I. Celik and C. Freitas, eds, Benchmark Test Cases for Computational Fluid Dynamics, Vol. 93, ASME FED, 1990.

[2] D. Goldstein, D. Hughes, R. Johnson and D. Lankford, eds, Data for Validation of CFD Codes, Vol. 146, ASME FED, 1993.

[3] I. Celic, Y. Hassan, D. Hughes, R. Johnson and M. Sommerfeld, eds, Experimental and Computational Aspects of Validation of Multiphase Flow CFD Codes, Vol. 180, ASME FED, 1994.
[4] CFD Online, http://www.cfd-online.com/Resources/.

[5] T.L. Geers, An objective error measure for the comparison of calculated and measured transient response histories, Shock and Vibration Bulletin 54(2) (1984), 99-107.

[6] B. Whang, W.E. Gilbert and S. Zilliacus, Two visually meaningful correlation measures for comparing calculated and measured response histories, Shock and Vibration 1(4) (1994), 303-316.

[7] D.M. Russell, Error measures for comparing transient data: Part I: Development of a comprehensive error measure, in: Proc. 68th Shock and Vibration Symposium, 1997, pp. 175184.

[8] D.M. Russell, Error measures for comparing transient data: Part II: Error measures case study, in: Proc. 68th Shock and Vibration Symposium, 1997, pp. 185-198.

[9] W. Herrmann, APRICOT code comparisons, critique of results for first phase, Sandia Laboratory, Report SAND-770089, 1977.

[10] M.S. Plesset and A. Prosperetti, Bubble dynamics and cavitation, Annual Review of Fluid Mechanics 9 (1977), 145-185.

[11] R. Courant and K.O. Friedrichs, Supersonic Flow and Shock Waves, Springer-Verlag, 1985, p. 424.

[12] W. Pohl, M.J.v.d. Hoek, J.P. Buis, C.J.L. Florie, S.L. Hancock, P.H.L. Groenenboom, D.J.E. Hesselink, H. Lenselink and P.J.J. Schaffers, The PISCES software for defense - A survey of PISCES code applications for defense-oriented computational problems, PISCES International B.V., 1984.

[13] A.B. Wardlaw, Jr., R.M. McKeown and H.T. Chen, Implementation and application of the P- $\alpha$ equation of state in the DYSMAS code, Naval Surface Warfare Center, Technical report NSWCDD/TR-95/107, 1996.

[14] A.B. Wardlaw, Jr. and H.U. Mair, One-dimensional benchmark solutions for underwater explosion bubble simulations, in: Proc. 67th Shock and Vibration Symposium, 1996, pp. 335-344.

[15] A.B. Wardlaw, Jr. and H.U. Mair, Spherical solutions of an underwater explosion bubble, Shock and Vibration 5(2) (1998), 89-102.

[16] G.I. Taylor, The pressure and impulse of submarine explosion waves on plates, in: Underwater Explosion Research, Vol. I, Office of Naval Research, 1950, pp. 1155-1173.

[17] R.S. Schechter and R.L. Bort, The response of two fluidcoupled plates to an incident pressure pulse, Naval Research Laboratory, Memorandum report 4647, 1981.

[18] H.G. Snay and E.A. Christian, The response of air-backed plates to high-amplitude underwater shockwaves, NAVORD, Report 2462, 1952.

[19] H.H. Bleich and I.S. Sandler, Interaction between structures and bilinear fluids, Int. J. of Solids and Structures 6 (1970), 617-639.

[20] H. Huang, Transient bending of a large elastic plate by an incident spherical pressure wave, J. of Applied Mechanics 41(3) (1974), 772-776.

[21] W.W. Murray, Interaction of a spherical acoustic wave with a beam of circular cross section, Underwater Explosions Research Division, Report 1-55, 1955.

[22] H. Huang, Transient interaction of plane acoustic waves with a spherical elastic shell, The J. of the Acoustical Society of America 45(3) (1969), 661-670. 
[23] H. Huang, Y.P. Lu and Y.F. Wang, Transient interaction of spherical acoustic waves and a spherical elastic shell, J. of Applied Mechanics (March 1971), 71-74.

[24] H. Huang and H.U. Mair, Neo-classical solution of transient interaction of plane acoustic waves with a spherical elastic shell, Shock and Vibration 3(2) (1996), 85-98.

[25] H. Huang, Transient response of two fluid-coupled spherical elastic shells to an incident pressure pulse, The J. of the Acoustical Society of America 65(4) (1979), 881-887.

[26] H. Huang, An exact analysis of the transient interaction of acoustic plane waves with a cylindrical elastic shell, J. of Applied Mechanics 37 (December 1970), 1091-1099.

[27] H. Huang and Y.F. Wang, Transient interaction of spherical acoustic waves and a cylindrical elastic shell, J. of the Acoustical Society of America 48(1) (1970), 228-235.

[28] H. Huang, Transient response of two fluid-coupled cylindrical elastic shells to an incident pressure pulse, J. of Applied Mechanics 46(3) (September 1979), 513-518.

[29] P. Zhang and T.L. Geers, Excitation of a fluid-filled, submerged spherical shell by a transient acoustic wave, $J$. of the Acoustical Society of America 93 (1993), 696-705.

[30] T.L. Geers, P. Zhang and B.A. Lewis, Advanced DAA methods for shock response analysis, Defense Nuclear Agency Technical report DNA-TR-91-69, July 1992.

[31] T.L. Geers and T.-H. Ju, A computer program for a canonical problem in underwater shock, Shock and Vibration 1(4) (1994), 331-337.

[32] J.B. Jones-Oliveira, Transient analytic and numerical results for the fluid-solid interaction of prolate spheroidal shells, J. of the Acoustical Society of America 99(1) (1996), 392-407.

[33] D.S. Nokes, Analysis of prolate spheroidal shell under undex load, Defense Nuclear Agency, Technical report DNA-TR-90171, 1992.

[34] R.S. Price, Similitude equations for explosives fired underwater, Naval Surface War-fare Center, Technical report NSWC TR 80-299, 1979.

[35] A.T. Ellis, Parameters affecting cavitation and some new methods for their study, California Institute of Technology, Report E-115.1, 1965.

[36] C.L. Kling, A high-speed photographic study of cavitation bubble collapse. Ph.D. thesis, University of Michigan, Ann Arbor, 1970.

[37] J.R. Blake and D.C. Gibson, Cavitation bubbles near boundaries, Annual Review of Fluid Mechanics 19 (1987), 99-123.

[38] G.L. Chahine, G.S. Frederick, C.J. Lambrecht, G.S. Harris and H.U. Mair, Spark-generated bubbles as laboratory-scale models of underwater explosions and their use for validation of simulation tools, in: Proc. 66th Shock and Vibration Symposium, Vol. II, 1995, pp. 265-274.

[39] G.L. Chahine, Etude asymptotique et experimentale des oscillations et du collapse des bulles de cavitation, Docteur Ingenieur Thesis, Universite Pierre et Marie Curie, Paris VI, December 1974. Also ENSTA, Report No. 042, 1974.

[40] G.L. Chahine, Experimental and asymptotic study of nonspherical bubble collapse, Applied Scientific Research 38 (1982), 187-197.

[41] G.L. Chahine, Interaction between an oscillating bubble and a free surface, J. of Fluids Engineering 99 (1977), 709-716.
[42] P. Gefken, A. Florence and M. Sanai, Spherical waves in saturated sand, Naval Surface Warfare Center, Contract report.

[43] H.G. Snay, J.F. Goertner and R.S. Price, Small scale experiments to determine migration of explosion gas globes towards submarines, NAVORD, Report 2280, 1952.

[44] J.A. Goertner, Effect of charge burial on explosive shock propagation: small-scale tests against shallow targets and buried mines, Naval Surface Warfare Center, Indian Head Division, Report IHCR 97-60, 1997.

[45] T. Young, Documentation of SAMSI tests conducted at WES, Naval Surface Warfare Center, Indian Head Division, 1996.

[46] B. Fiessler and R. Chwalinski, On the influence of structural shape and interaction on explosive loads in shock and collapse phases, in: Proc. 66th Shock and Vibration Symposium, Vol. II, 1995, pp. 287-295.

[47] J.F. Goertner, R. Thrun and J.E. Berry, Underwater explosion bubble collapse against a flat plate. 1987 NSWC Hydrotank Test Series Pressure Data Report, Naval Surface Warfare Center, Technical report NSWCDD/TR-93/98, 1993.

[48] R. Thrun, J. Goertner and G. Harris, Underwater explosion bubble collapse against a flat plate, Naval Surface Warfare Center, Technical report NSWCDD/TR-92/482, 1993.

[49] R.M. Schmidt, M.E. Voss, K.R. Housen and K.A. Holsapple, Subscale experiments to measure shock and bubble loading on responding structures, Sloshing, Fluid-Structure Interaction and Structural Response Due to Shock and Impact Loads 1994, ASME PVP-Vol. 272.

[50] G.S. Harris, Naval Surface Warfare Center, Indian Head Division, unpublished data on Pipe Whip experiment.

[51] G.L. Chahine, C.J. Lambrecht, K.M. Kalumuck, G.S. Frederick and P.D. Aley, An experimental study of the influence of structural deformation on water jet impact loading, Dynaflow report 92001-7, 1995.

[52] M. Talley and D. Mills, Internal fluid models, Naval Surface Warfare Center, Report CARDEROCKDIV-SSM-6994/8, 1994

[53] C. McClure, Preliminary report on explosive field tests in support of the hull deformation/rupture study, Naval Surface Warfare Center, Technical note NSWCDD/TN-93/34, 1993.

[54] U. Andelfinger, Simulations of underwater explosions against submerged structures using the DYSMAS/ELC code - Part A, in: Proc. 65th Shock and Vibration Symposium, Vol. II, 1994, pp. 243-251.

[55] D. Ranlet and R.P. Daddazio, A submerged shock response problem suitable for use as a benchmark, 1997, http://www.wai.com/AppliedScience/Software/Elshok/ ONR_Cylinder.pdf.

[56] M.W. Lewis and T.L. Wilson, Response of a water-filled spherical vessel to an internal explosion, Los Alamos, Draft report, 1996.

[57] W.S. Pellini, Use and interpretation of the NRL explosion bulge test, NRL, Report 4034, September 4, 1952.

[58] L.N. Gifford, J.R. Carlberg, A.J. Wiggs and J.B. Sickles, Explosive testing of full thickness precracked weldments, David Taylor Research Center, Report DTRC-SSPD-88-17242, 1988.

[59] M.A. Talley, Deep depth UNDEX simulator study, in: Proc. 62nd Shock and Vibration Symposium, Vol. IV, 1991, pp. 807$807 \mathrm{~T}$. 
[60] A. Shima, Y. Tomita, D.C. Gibson and J.R. Blake, The growth and collapse of cavitation bubbles near composite surfaces, J. of Fluid Mechanics 203 (1989), 199-214.

[61] H. Sandusky, Dynamic measurements of plastic deformation in a water-filled aluminum tube in response to detonation of a small explosive charge, in: Proc. 67th Shock and Vibration Symposium, 1996.

[62] G. Chambers, H. Sandusky, F. Zerrilli, K. Rye and R. Tussing, Pressure measurements on a deforming surface in response to an underwater explosion, CP429, in: Shock Compression of Condensed Matter, Schmidt, Dandekar and Forbes, eds, The American Institute of Physics, 1998.

[63] J.E. Slater and G. Rude, Experimental study of fluid-structure interaction during close-proximity underwater explosions, in: Proc. ASME PVP-96 Conference on Structures nder Extreme Loading Conditions, PVP, Vol. 325, 1996, pp. 1-10.

[64] T.L. Geers, Residual potential and approximate methods for three dimensional fluid structure interaction problems, $J$. of the Acoustical Society of America 49 (1971), 1505-1510.

[65] T.L. Geers, Doubly asymptotic approximations for transient motions of submerged structures, The J. of the Acoustical Society of America 64 (1978), 1500-1508.

[66] T.L. Geers and P. Zhang, Doubly asymptotic approximations for submerged structures with internal fluid volumes, J. of Applied Mechanics 61 (1994), 893-906.

[67] S. Zilliacus, T. Toridis and T. Giacofci, Analysis of wave excited submerged structure, David W. Taylor Naval Ship Research and Development Center, Report 79-175-19, June 1979; also in: Proc. ADINA Conf., MIT, 1979, pp. 425-446.

[68] S. Zilliacus, Fluid-structure interaction and ADINA, Computers \& Structures 17(5/6) (1983), 763-773.

[69] R.D. Miller, On the explicit modeling of fluid regions using DYNA/DAA, in: Proc. 64th Shock and Vibration Symposium, Vol. I, 1993, pp. 435-445.

[70] R.D. Miller, E.T. Moyer and G.G. Amir, UNDEX response prediction using DYNA/DAA with $\mathrm{DAA}_{2}$, in: Proc. 64th Shock and Vibration Symposium, Vol. I, 1993, pp. 446-456.

[71] R.D. Miller, On the fluid-structure coupling features of DYNA/DAA using a reduced fluid mesh (RFM), in: Proc. 65th Shock and Vibration Symposium, Vol. I, 1994, pp. 207216.

[72] R. Vasudevan and D. Ranlet, Submerged shock response of a linearly elastic shell of revolution containing internal structure - user's manual for the ELSHOK code, Defense Nuclear Agency, Report DNA-TR-81-184, 1982.

[73] Weidlinger Associates, http://www.wai.com/AppliedScience/ Software/Elshok/elshok-brochure.html.

[74] R.P Daddazio, R.S. Atkatsh, I.S. Sandler, S. Chans, K.G. Stultz, Jr., D. Ranlet and R. Smilowitz, Inelastic response of structures subjected to underwater explosions, in: Proc. 2nd Asia-Pacific Conf. on Shock \& Impact Loads, 1997.

[75] D. Ranlet and J.M. McCormick, Transient response of submerged shells of finite length to full envelopment type shock waves, Part II: Comparison of predictions and meas-ured test results for side-on loading, Weidlinger Associates, Technical report No. 14, 1974.
[76] D. Ranlet, H.H. Bleich, F.L. DiMaggio and M.L. Baron, Transient response of submerged shells of finite length to full envelopment type shock waves, Part IV: Comparison of predictions and measured test results for side-on loading of a shell containing internal structure - Configuration 1, Weidlinger Associates, Technical report No. 17, December 1974.

[77] D. Ranlet and R.P. Daddazio, A submerged shock response problem suitable for use as a benchmark, in: Proc. 68th Shock and Vibration Symposium, 1997, pp. 96-104.

[78] R.S. Atkatsh, M.P. Bieniek and M.L. Baron, Dynamic elastoplastic response of shells in an acoustic medium - EPSA code, Int. J. of Numerical Methods in Engineering 19 (1983), 811824.

[79] R. Atkatsh, K.K. Chan, R. Daddazio and D. Ranlet, Theoretical developments for the EPSA computer program, Defense Nuclear Agency, Technical report DNA-TR-87-155, 1987.

[80] R.S. Atkatsh, K.K. Chan and K.G. Stultz, Jr., EPSA reference manual, Defense Nuclear Agency, Report DNA-TR-91-119, 1992.

[81] R.S. Atkatsh, K.K. Chan, K.G. Stultz, Jr., R. Dillworth and M.L. Miranda, EPSA-II Input Handbook - Revision G, Weidlinger Associates, 1994.

[82] Weidlinger Associates, http://www.wai.com/AppliedScience/ Software/Epsa/index-epsa.html.

[83] K.K. Chan, K.G. Stultz and R. Atkatsh, Dynamic inelastic shell analysis, Mechanics of Materials and Structures 35 (1994), 143-158.

[84] K.K Chan and R.S. Atkatsh, EPSA topics: transient response of submerged spherical shells, in: Proc. 62nd Shock and Vibration Symposium, Vol. III, 1991, pp. 578-586.

[85] K.J. Stultz, Jr. and R.S. Atkatsh, Single hull versus double hull design shock response of underwater vessels, Defense Nuclear Agency, Technical report DNA-TR-94-152, 1996.

[86] R. Dawson, A comparison of internal fluid model experimental data and predicted responses by applying the geers error function, Carderock Division, Naval Surface Warfare Center, Report SSPD-93-177-5, October 1992.

[87] K.G. Stultz, Jr., R.S. Atkatsh and K.K. Chan, Single hull versus double hull design shock response of underwater vessels, in: Proc. 65th Shock and Vibration Symposium, Vol. II, 1994, pp. 209-218.

[88] K.G. Stultz, Jr., R.S. Atkatsh and K.K. Chan, Single hull versus double hull design shock response of underwater vessels, Defense Nuclear Agency, Technical report DNA-TR-94-152, February 1996.

[89] R.P. Daddazio, K.G. Stultz and K.K. Chan, Dynamic inelastic shock analysis of submerged stiffened shells using EPSA, in: Proc. 60th Shock and Vibration Symposium, Vol. V, 1989, pp. 153-166.

[90] Hibbitt/Karlsson \& Sorensen, ABAQUS - Example Problems Manual Version 5.2, 1992; http://www.abaqus.com/products/ p_abusa.html.

[91] G.C. Everstine, The USA/NASTRAN interface for underwater shock analysis - third edition, Carderock Division, Naval Surface Warfare Center, Report CDNSWC/SSD-93/05, 1993.

[92] H. Nielsen, G.C. Everstine and Y.F. Wang, Transient response of a fluid-coupled double spherical shell structure to an incident pressure pulse, The J. of the Acoustical Society of America 70 (1981), 1776-1782. 
[93] T.S. Littlewood, K.W. Froling and C.J. Abate, Comparison of shock test data with computational predictions: The ONR cylinder shock test series - refined analysis of the sideon attack geometry, General Dynamics Electric Boat, Report TNAM-88-05, 1988.

[94] Y.S. Shin and L.D. Santiago, Surface ship shock modeling and simulation: two-dimensional analysis, Shock and Vibration 5(2) (1998), 129-137.

[95] J.A. DeRuntz and F.A. Brogan, Underwater shock analysis of non-linear structures, a reference manual for the USA-STAGS code, Lockheed Palo Alto Research Laboratory, Report No. LMSC-D633864, 1979.

[96] J.A. DeRuntz, Shock analysis of submerged structures with internal fluid volumes, Sloshing, Fluid-Structure Interaction and Structural Response due to Shock and Impact Loads 1994, ASME PVP, Vol. 272 (1994), 141-152.

[97] C.A. Felippa and J.A. DeRuntz, Finite element analysis of shock-induced hull cavitation, Computer Methods in Applied Mechanics and Engineering 44 (1984), 297-337.

[98] J.A. DeRuntz, Jr., The underwater shock analysis code and its applications, in: Proc. 60th Shock and Vibration Symposium, Vol. I, 1989, pp. 89-107.

[99] M.E. Giltrud and D.S. Lucas, A numerical comparison with an exact solution for the transient response of a cylinder immersed in a fluid, The Shock and Vibration Bulletin 49 (1979).

[100] M.E. Giltrud, The numerical prediction of the dynamic response of a cylindrical shell in an acoustic medium, Naval Surface Weapons Center, Technical report NSWC TR 79-287, 1980.

[101] K.C. Kiddy, Transient interaction of fluid-coupled elastic shell systems using fluid finite elements, Naval Surface Warfare Center, Technical report NSWC TR 81-153, 1981.

[102] T.S. Littlewood, Underwater shock analysis of fluid-filled structures using the USA code with a symmetric potential fluid formulation, General Dynamics Electric Boat Division, Report TN-AM-88-08, 1988.

[103] C.A. Felippa, T.L. Geers and J.A. DeRuntz, Response of a ring-stiffened cylindrical shell to a transient acoustic wave, Lockheed Palo Alto Research Laboratory, Report LMSCD403671, 1974.

[104] Lawrence Livermore National Laboratory, http://www. llnl.gov/bdiv/ale $3 \mathrm{~d} /$.

[105] R. Couch and D. Faux, Simulation of underwater explosion benchmark experiments with ALE3D, Lawrence Livermore National Laboratory, Report UCRL-CR-123819, 1996.

[106] P. Yarrington, The CTH-EPIC link - a coupled Eulerian/Lagrangian computational method, in: Proc. 12th U.S. National Congress on Computational Mechanics, 1994.

[107] Quetzal Computational Associates, Zapotec: A code to perform coupled Eulrian/Lagrangian solid dynamics hydrocode calculations, http://www.quetzalcoatl.com/zapotec.html.

[108] S. Poy, Numerical simulations of underwater explosions (UNDEX) using Eulerian, Lagrangian, and arbitrary LagrangianEulerian formulations, Naval Surface Warfare Center, Carderock Division, Technical report NSWCCD-FOUO-TR-67 96/05, 1996
[109] R.G. Whirley and J.O. Hallquist, DYNA3D - a nonlinear, explicit, three-dimensional finite element code for solid and structural mechanics - user manual, Lawrence Livermore National Laboratory, Report UCRL-MA-107254, 1991.

[110] H.J. Schittke, W. Mohr, H. Luetje, W.E. Pfrang, J. Freercks and E. Niessen, The program DYSMAS/ELC and its application on underwater shock loading of vessels, in: Proc. 60th Shock and Vibration Symposium, Vol. IV, 1989, pp. 55-78.

[111] A.B. Wardlaw, Jr., B. Fiessler and D.K. Han, Hydrocode simulation of the Seneca lake flat plate test, in: Proc. 65th Shock and Vibration Symposium, Vol. III, 1994, pp. 81-89.

[112] B. Fiessler, D.K. Han and A.B. Wardlaw, Jr., Coupled hydrocode simulation of the Seneca lake flat plate test, in: Proc. 66th Shock and Vibration Symposium, Vol. III, 1995, pp. 219227.

[113] R.M. McKeown, R. Grande and J.M. Mentges, Simulations of underwater explosions against submerged structures using the DYSMAS/ELC code - Part B: Analysis of an unstiffened cylinder, in: Proc. 65th Shock and Vibration Symposium, Vol. II, 1994, pp. 253-261.

[114] A. Wardlaw, Jr., R. McKeown and A. Luton, Coupled hydrocode prediction of underwater explosion damage, in: 48th Bomb and Warhead Conference, May 1999.

[115] B. Fiessler, IABG, unpublished simulation of Apricot\#1 using DYSMAS/E, 1991

[116] A.B. Wardlaw, Jr., Far field boundary conditions for underwater explosions, Dahlgren Division, Naval Surface Warfare Center, Technical report NSWCDD/TR-94/20, 1994.

[117] B. Fiessler, IABG, unpublished simulation of cavitated water impact using DYSMAS/E, 1991.

[118] G.R. Johnson, R.A. Stryk, E.H. Petersen, T.J. Holmquist, J.A. Schonhardt and C.R. Burns, User instructions for the 1995 version of the EPIC code, Alliant Techsystems, 1994.

[119] K.C. Kiddy, A comparison of EPIC-2 calculations with the underwater shock wave similitude equations for pentolite, Naval Surface Warfare Center, Technical report NSWC TR 84-496, 1985.

[120] K.C. Kiddy, Calculation of the response of elastic structures to underwater explosions using Lagrangian hydrocodes, The Shock and Vibration Bulletin 57(3) (1987), 1-10.

[121] J. Ahmad, K. Wong and J. Porter, Nonlinear dynamic analysis assessment of explosively-loaded submarine hull panels, in: Proc. 60th Shock and Vibration Symposium, Vol. I, 1989, pp. 139-171.

[122] J.O. Hallquist, D.W. Stillman and T.-L. Lin, LS-DYNA3D user's manual, Livermore Software Technology Corporation, Report 1007, Revision 3, 1994.

[123] J.O. Hallquist, LS-DYNA3D theoretical manual, Livermore Software Technology Corporation, Report 1018, 1991

[124] MacNeal-Schwendler Corporation, MSC/DYTRAN 3.0 user's manual, 1996.

[125] MacNeal-Schwendler Corporation, http://www.mechsolutions.com/products/dytran/index.html.

[126] J.E. Chisum and Y.S. Shin, Multimaterial Eulerian and coupled Lagrangian-Eulerian finite element analysis of underwater shock problems, Naval Postgraduate School, Report NPSME-95-001, 1995. 
[127] Y.S. Shin and J.E. Chisum, Modeling and simulation of underwater shock problems using a coupled Lagrangian-Eulerian analysis approach, Shock and Vibration 1(4) (1997), 1-10.

[128] H. Lenselink and E. de Vries, Analysis of the loading of an aluminum cylinder by an underwater explosion, in: 1994 MSC World Users' Conference, 1994.

[129] J.W. Swegle, S.W. Attaway, M.W. Heinstein, F.J. Mello and D.L. Hicks, An analysis of smoothed particle hydrodynamics, Sandia National Laboratory, Report SAND93-2513/UC-705, 1994.

[130] J.W. Swegle and S.W. Attaway, On the feasibility of using smoothed particle hydro-dynamics for underwater explosion calculations, Sandia National Laboratory, Report SAND950311/UC-705, 1995.

[131] K.M. Kalumuck, R. Duraiswami and G.L. Chahine, Bubble dynamics fluid-structure interaction simulation by coupling fluid BEM and structural FEM codes, J. of Fluids and Structures 9 (1995), 861-883.

[132] K.M. Kalumuck, G.L. Chahine and R. Duraiswami, Analysis of the response of a deformable structure to underwater explosion bubble loading using a fully coupled fluid-structure interaction procedure, in: Proc. 66th Shock and Vibration Symposium, Vol. II, 1995, pp. 277-286.

[133] G.L. Chahine, R. Duraiswami and K.M. Kalumuck, Boundary element method for calculating 2D and 3D underwater explosion bubble loading on nearby structures including fluid structure interaction effects, Naval Surface Warfare Center, Technical report NSWCDD/TR-93/46, 1996.

[134] G.L. Chahine and R. Duraiswami, Boundary element method for calculating 2D and 3D underwater explosion bubble behavior in free water and near structures, Naval Surface Warfare Center, Technical report NSWCDD/TR-93/44, 1994.

[135] G.L. Chahine, T.O. Perdue and C.B. Tucker, Interaction between an underwater explosion bubble and a solid submerged body, Dynaflow, Inc., Technical report 89001-1, 1989.

[136] G.L. Chahine, A numerical model for three-dimensional bubble dynamics in complex configurations, in: Proc. 22nd American Towing Tank Conf., St. Johns, Newfoundland, Canada, 1989, pp. 61-67.
[137] G.L. Chahine, Dynamics of the interaction of non-spherical cavities, in: Mathematical Approaches in Hydrodynamics, T. Miloh, ed., SIAM, 1991, pp. 51-67.

[138] G.L. Chahine, S. Prabhukumar and R. Duraiswami, Bubble dynamics near a cylindrical body: 3D boundary element simulation of the ONR Snay/Goertner bubble benchmark problems, in: Proc. 67th Shock and Vibration Symposium, Vol. III, 1996, pp. 215-224.

[139] M.W. Lewis and B.A. Kashiwa, Fluid-structure interaction modeling, in: The Joint DoD/DOE Munitions Technology Development Program (Progress Report for FY93), Los Alamos National Laboratory, Report LA-12806-PR, Vol. I, 1994.

[140] M.W. Lewis and B.A. Kashiwa, Fluid-structure interaction modeling, in: The Joint DoD/DOE Munitions Technology Development Program, Progress Report for FY94, Los Alamos National Laboratory, Report LA-12960-PR, Vol. I, 1995.

[141] B.A. Kashiwa, M.W. Lewis and T.L. Wilson, Fluid-structure interaction modeling, Los Alamos National Laboratory, Report LA-13111-PR, Vol. I (draft), 1996.

[142] J.J. Dike, P.S. Jin, V.D. Revelli and W.P. Trento, Linking a hydrodynamic code and a finite element code to predict underwater explosion damage, Sandia National Laboratory, Report SAND 92-8619/UC-705, 1993.

[143] W.G. Szymczak, J.M. Solomon and A.E. Berger, BUB3D - description of mathematical model, algorithms, and user's guide, Naval Surface Warfare Center, Technical report NSWCDD/TR-95/42, 1997.

[144] W.G. Szymczak, Computations and experiments of pressure loadings form underwater explosion bubbles, ASME PVP 1997 Structures Under Extreme Loading Conditions, PVP 351, 1997.

[145] Combustion Dynamics Ltd., Explosion and combustion analysis software: IFSAS, http://www.combdyn.com/ifsas.htm.

[146] J.E. Slater and D.A. Erickson, Analysis of fluid-structure interaction during underwater explosions, in: Proc. 4th Canadian CFD Conf., 1996, pp. 287-292. 

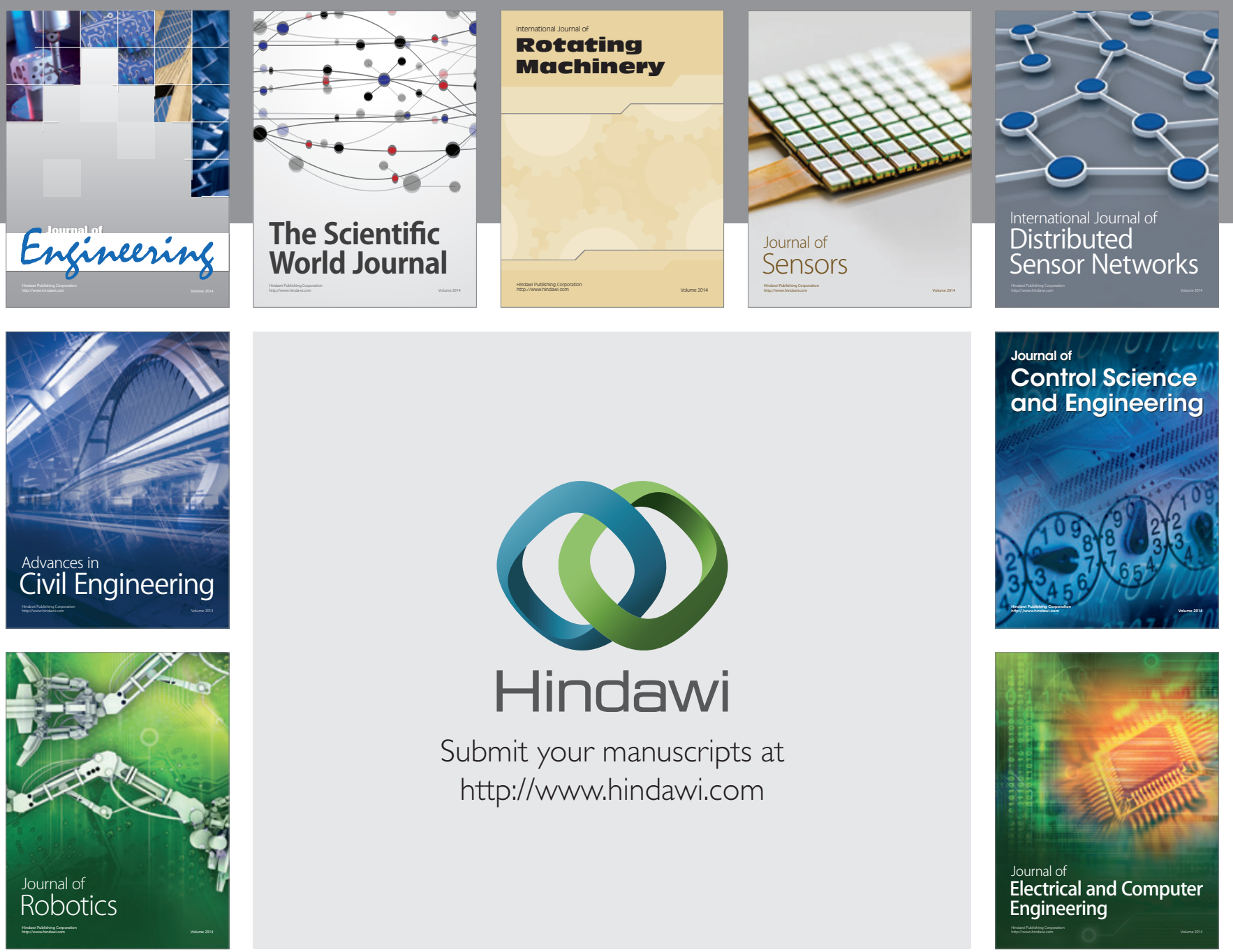

Submit your manuscripts at

http://www.hindawi.com
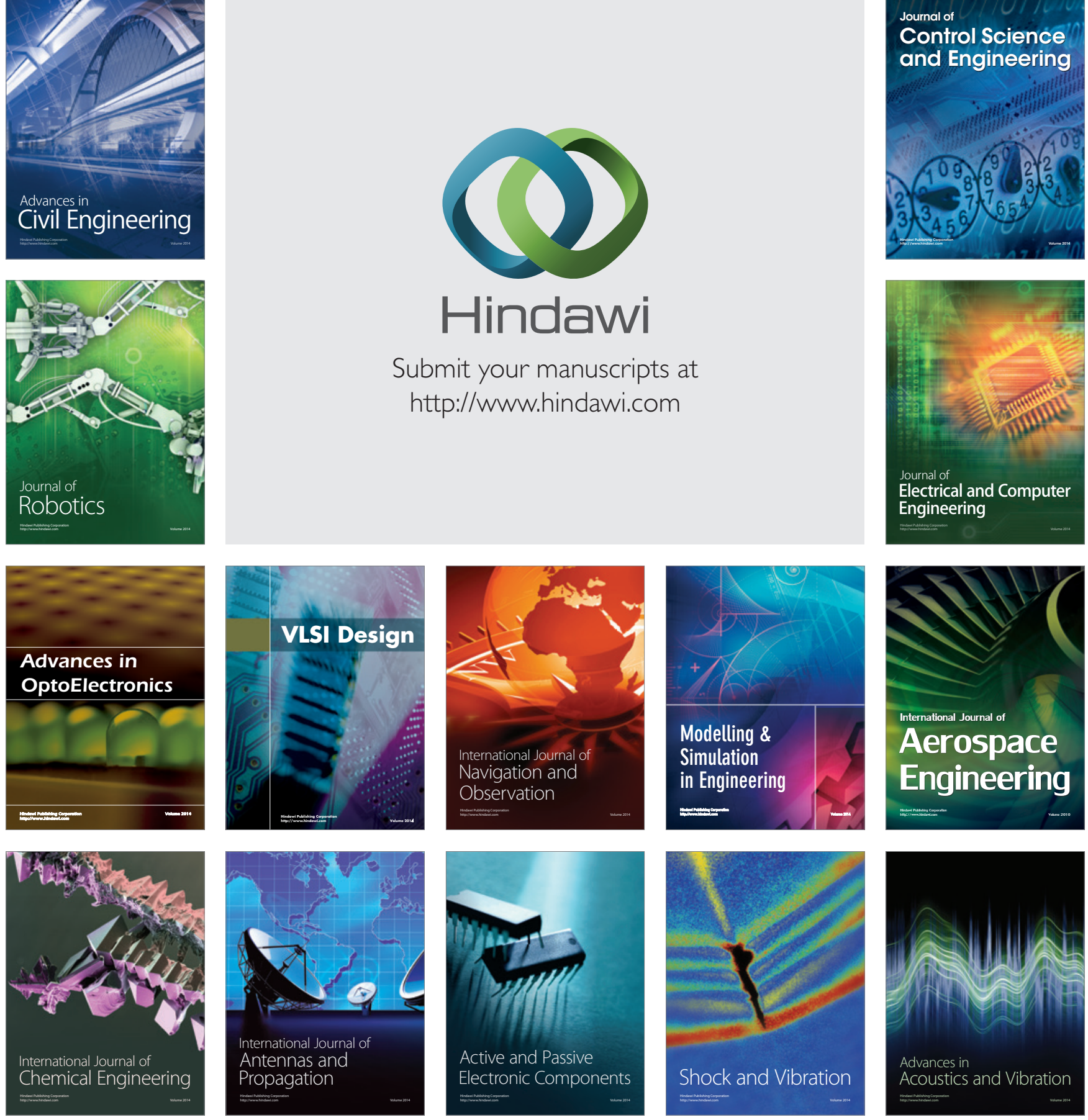